\title{
Impact of regular physical activity and sports on school performance among girls and boys aged between 6 and 10 years \\ Impacto de la actividad física regular y los deportes en el rendimiento escolar entre niñas y niños de entre 6 y 10 años \\ Amina Kheira Bekhechi, Belkacem Khiat \\ Université des Sciences et de la Technologie d’Oran Mohamed Boudiaf (Algérie)
}

\begin{abstract}
This longitudinal study seeks to show if sport has an impact on the school results and also on cognitive functioning, and if this causal link is significantly important. An experimental group of 55 students that practice out-of-school sports, at a rate of 3 times a week and a reference group of 55 students that don't practice out of school sports, their age is between 6 and 10 years old, both male and female from an elementary schools of the town of Oran (Algeria), they were followed during 15 month (five quarters). The socio-demographic data were collected by a questionnaire intended for the students of the two groups, and the administrative school results at the end of each quarter. An intelligence test of the CPM (Raven's Coloured Progressive Matrices) was administered at the end of the fifth trimester to assess the main cognitive abilities in both groups. Students that practice out-of-school sports have general school averages and a significantly higher level of intelligence than students that don't $(p<0.05)$ where sport girls have overall academic averages significantly higher than sport boys $(p=0.025)$. As noted by many similar studies, the practice of a physical-activity and sport regular seem to have a very positive impact on the academic performance and also on cognitive functioning.

Keywords: Academic performance; Cognitive functioning; Physical-activity and sport; Provided education for children; Raven’s Coloured Progressive Matrices (CPM).
\end{abstract}

Resumen. Este estudio longitudinal busca mostrar si el deporte tiene un impacto en los resultados escolares y también en el funcionamiento cognitivo, y si este vínculo causal es significativamente importante. Un grupo experimental de 55 estudiantes que practican deportes fuera de la escuela, a una tasa de 3 veces por semana y un grupo de referencia de 55 estudiantes que no practican deportes fuera de la escuela, su edad es entre 6 y 10 años, Tanto hombres como mujeres de una escuela primaria de la ciudad de Orán (Argelia), fueron seguidos durante 15 meses (cinco cuartos). Los datos socio demográfico se recopilaron mediante un cuestionario destinado a los estudiantes de los dos grupos y los resultados de la escuela administrativa al final de cada trimestre. Se administró una prueba de inteligencia de CPM (Matrices progresivas de color de Raven) al final del quinto trimestre para evaluar las principales habilidades cognitivas en ambos grupos. Los estudiantes que practican deportes fuera de la escuela tienen promedios escolares generales y un nivel de inteligencia significativamente más alto que los estudiantes que no lo hacen $(p<0.05)$ donde las chicas deportistas tienen promedios académicos generales significativamente más altos que los varones deportivos $(p=0.025)$. Como lo observaron muchos estudios similares, la práctica de una actividad física y un deporte regular parecen tener un impacto muy positivo en el rendimiento académico y también en el funcionamiento cognitivo.

Palabras clave: Rendimiento académico; Funcionamiento cognitivo; La actividad física y el deporte; Proporcionó educación para los niños; Matrices progresivas de colores de Raven (CPM).

\section{Introduction}

The practice of the physical exercise was classically associated with improvements of the metabolic functions such as cardiovascular, ventilator, hormonal (Donnelly \& Lambourne, 2011; Haapala et al., 2017). Recent evidence shows how the effects of the physical-activity on the brain can create positive results as the improvement of the attention, the memory and the executive functions (De Greeff et al., 2018 ; Esteban-Cornejo et al., 2015 ; Tomporowski et al., 2011; Van der Niet et al., 2014). These last years, many studies brought back the relation between the physical exercise and the notes obtained at primary, secondary and academic education levels (Álvarez-Bueno et al., 2016; Maureira \& Diaz, 2017).

The physical-activity seems to have a positive effect on other determinants of academic success like the behavior in class, the self-esteem, the self-image, satisfaction towards the school, the feeling of member ship of the school and their social interactions. Research showed that regular physicalactivity improves the school results and the productivity of the students, just as their capacity to be focused for long periods (De Greeff et al., 2018). The daily physical-activity improves the output of the students and supports their academic success, stimulates their memory, their direction of observation and develops their capacity to solve problems and to make decisions; it also clearly controls the problems of behavior, by adopting a positive attitude and by having the direction of the creativity (Álvarez-Bueno et al., 2016; Álvarez-Bueno et al., 2017; Bangsbo et al., 2016).

We cannot think that the simple sport promotes the development of appropriate values, it is necessary to work intentionally this aspect so that the relationship is positive (Aguado et al., 2015).

It is suggested that the beneficial effects of the physicalactivity on the school output are ascribable to the improvement of the cognitive functions, such as the attention, the concentration and the working memory (Bezold et al., 2014; Esteban-Cornejo et al., 2014; Rasberry, 2011; Resaland et al., 2016).

This study seeks to show if the regular sports activity has a positive impact on the school results and if this causal link is significantly important. 


\section{Methods}

\section{Population}

On the whole, 110 students of the two sexes from 6 to 10 years old of 16 elementary schools, in class of second and third year with return to school 2015/2016 were selected. Students who were involved in this study after the written approval by their parents and the administration of the school, were divided into two groups: the experimental group (55 students) which profits from 3 weekly sessions of physicalactivity and sport out-of-school and the reference group (55 students) which does not practice any out of school physicalactivity and sport

\section{Experimental protocol}

A survey previously distributed to all teachers confirmed and validated the choice of the classes concerned: each class had to include experienced sports students, members of sports clubs and non-sports students.

A direct interview with each student was conducted in order to select the two groups, the same age, the same sex and the same socio-demographic level.

These two groups were followed from the first to the fifth trimester during two school years (2015-2016 and 2016-2017), by means of a survey submitted after each quarter: the document contains socio-demographic, school and sports data for each student which is as follows:

- The social level (working and non-separated parents, number of siblings, no health problems, average number of sleeping hours per night)

- School averages out of 10 (quarterly and both subjects: mathematics and Arabic language), non-doubling, no tutoring;

- School and extracurricular sports (nature and time);

In addition, a test on cognitive functioning (the CPM: Raven's Coloured Progressive Matrices) (Raven (1998)) was carried out by the two groups of students (sporting students and non-sporting students) after the last trimester (fifth quarter) and treated by a clinical psychologist.

Statistical method

Statistical analyzes were carried out on the SPSS software. Comparisons of means were made by statistical tests of the type Mann-Whitney U (2 samples) and ANOVA at one factor. The comparison between the two groups and the level of intelligence were measured by the Likert scale. For all the tests carried out the threshold of significance was set at $p<0.05$.

\section{Results}

Statistically and according to the Mann-Whitney U test, the difference is very significant $(p<0.05)$ for all school averages between the two groups (Figure 1).

There is a large difference in the overall school averages between sporting students and non-sporting students. The general quarterly, mathematics and Arabic language averages of the five quarters of the sports group are significantly higher than those of the non-sporting group (Figure 1).

In fact, sporting students have a general quarterly average of five quarters of 8.93 out of 10 against 5.99 out of 10

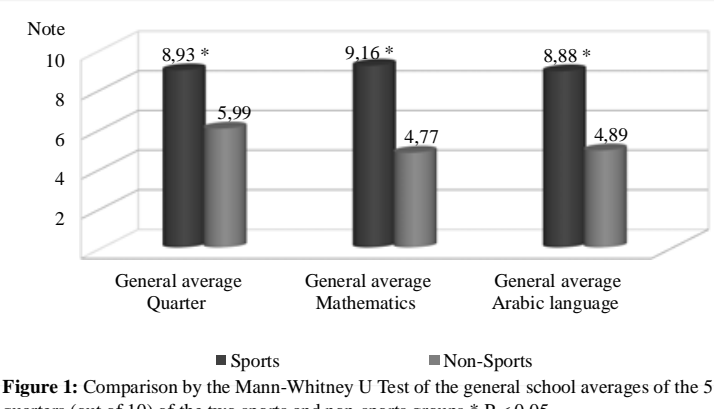

Figure 1: Comparison by the Mann-Whitney U Test of the general sch
quarters (out of 10) of the two sports and non-sports groups * $\mathrm{P}<0.05$

among non-sporting students. For the general averages of the five quarters of mathematics and the Arabic language, the sports group has a general average of 9.16 out of 10 against 4.77 in mathematics and 8.88 against 4.89 out of 10 in Arabic language.

Thus, the correlation between the overall average of the five quarters and the overall average of the five mathematics scores ( $r=0.72$ ) is very strong. There is also a strong correlation ( $r=0.81$ ) between the overall average of the five quarters and the overall average of the five scores of the Arabic language. That is, the relationship between the overall quarterly average of the five quarters and the overall average of the 5 scores of the Arabic language is stronger than the relationship between the overall quarterly average of the 5 quarters and the overall average of the five marks of mathematics.

For sporting students, the quarterly average is constant from the first to the fifth quarter. While among non-sporting students, the quarterly average is decreasing from the first to the fifth quarter particularly in the 4th and 5th quarter (Figure 2).

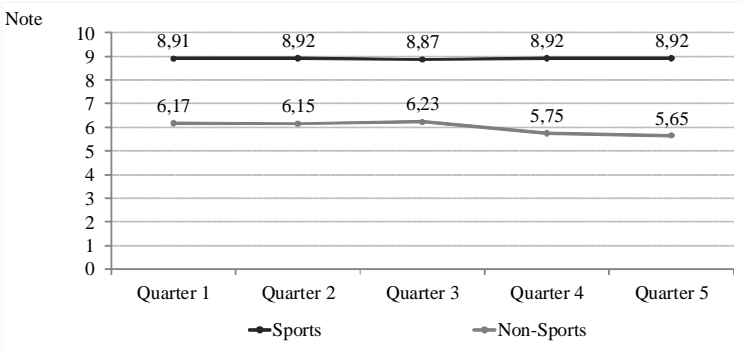

Figure 2: The evolution of the quarterly general averages of the 5 quarters (scores out of 10) of the two sports and non-sports groups

In the sports group, the general school averages of mathematics and the Arabic language are constant in the five quarters. While in the non-sports group there is a sharp decrease in the average in mathematics (from 5.43 to 3.96) and also for the Arabic language (from 5.28 to 4.4) in the five quarters (Figure 3).

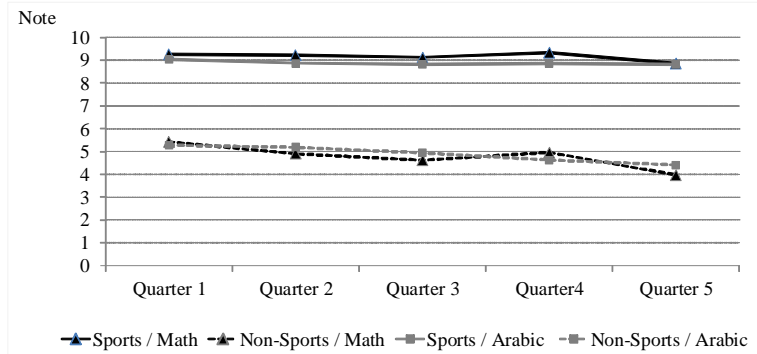

Figure 3: The evolution of the general school averages of mathematics and the arabic language of 5 quarters (scores of 10 ) of the two sports and non-sports groups 
Statistically and according to the Likert scale, the difference is very significant $(p<0.05)$ between the two groups for the level of intelligence. The Contingency coefficient $C c$ $=60 \%$. Sports students have an average intelligence «Above average» and non- sports students have a mean intelligence average.

There is a big difference in the level of intelligence between sports students and non-sports students (Table 1). It can be seen that $16.40 \%$ of sports students have a «Superior» level of intelligence compared to $0 \%$ of non- sports students. In addition, the level of intelligence «Above average» is 54.50 $\%$ among sports students against $0 \%$ among non-sports students. In the non-sporting group, the level of intelligence «Medium» dominates with $85.50 \%$ against $29.10 \%$ at the sports group. Finally, we note that $1.80 \%$ of non-sports students have a level of intelligence «Subnormal» (equals a student) against $0 \%$ in the sports group (Table 1 ).

According to the Mann-Whitney U test, in the sports group the overall quarterly average of girls is significantly higher than that of boys ( $p=0.025)$, and they are higher for each quarter (Table 2 ).

According to the $\div 2$ test of independence, there is a significant difference $(p=0.024)$ in the level of intelligence between girls and boys in the sports group: $77.80 \%$ of girls are in the category «Superior» compared to only $22.20 \%$ for boys (Table 3).

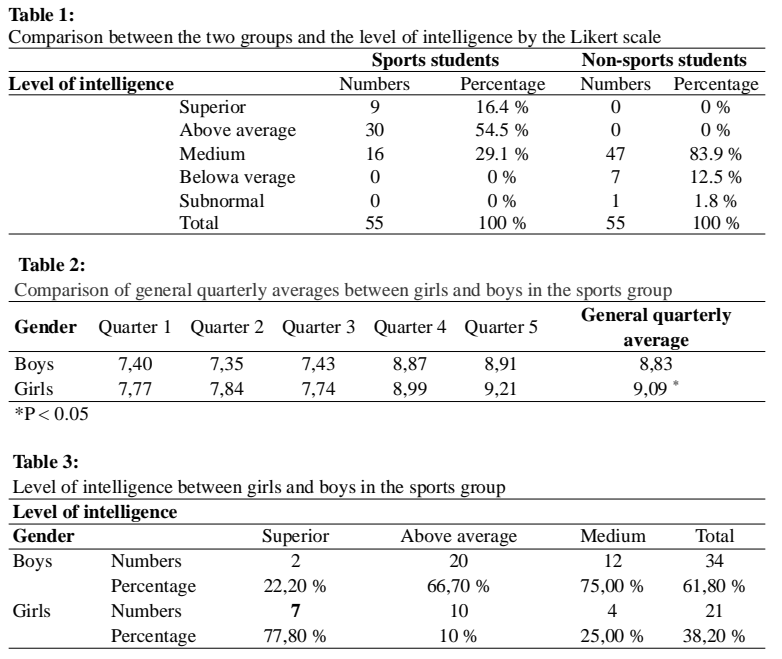

\section{Discussion}

Students who practice regular physical activity and sports, and although from different schools, have a general school average that is higher than that of non-practitioners. Thus, it appears that regular physical activity can improve concentration and academic performance, or even improve math, reading and writing scores (Donnelly et al., 2017; Haapala et al., 2017). The students who do physical activity perform better in school than those who do not (Singh et al., 2012; Van Dusen et al., 2011). In our study, this positive effect seems to be lasting since it is observed during the five school years of the study (Schmidt et al., 2017). On the other hand, the high level of intelligence level of sports students located «Above average» $(54.50 \%)$ confirms to some extent the influence of regular physical and sports practice as well on the achieving better academic results than cognitive functioning.

There is a difference in school averages between boys (8.83 / 10) and girls (9.09 / 10) (Tremblay, Inman \& Wilms, 2000), this can be explained by the fact that girls are more applied in their studies. The difference is much more pronounced for the level of intelligence: $77,80 \%$ of the girls are in the category «Superior» against only 22,20\% for the boys: thus the influence of the practice of a physical activity and sports The regular diet seems to have a greater impact on the cognitive aspects of girls compared to those of boys. Some recent studies have noted this finding (Donnelly et al., 2016).

In April 2017, 24 researchers from 8 different countries and different disciplines made a consensus statement on the benefits of physical activity on fitness, health, cognitive operation, the commitment, the motivation, the psychological wellness and the social inclusion of the children and the young ages from 6 to 18 years (Bangsbo et al., 2016; Morales et al., 2011). A positive association between the programs of physical exercises and academic performance has been reported more or less regularly in the literature and metaanalyzes (Álvarez-Bueno et al., 2016; Howie and Pate, 2012; Lambourne et al., 2013; Norris et al., 2015; Watson et al., 2017).

One of the elements which contribute to this durable influence seems to be the volume and the intensity of the meetings of sports (Marques et al., 2017; Oliveira et al., 2017; Tompkins et al., 2012; Wittberg et al., 2012). The very positive and stable school results in the time of the sporting students represent an additional argument to encourage the sporting practice out-of-school in the children (Sævarsson et al., 2017). This observation is more marked in mathematics compared to the Arab language (Álvarez-Bueno et al., 2017). Admittedly the beneficial of physical-activity and sporting impact on the health of the young people is undeniable, like his effect on the mental one and the social relations (Coe et al., 2013; Oliveira et al., 2017; Tomporowski et al., 2015), nevertheless we think that there is in our schools of the factors which are determining in this irrefutable fact. The over-populated classes, of the teachers little trained (and sometimes not formed by the whole) in pedagogy and didactic, a motivation to study very low students make that the latter do not concentrate very well in their training what lead them to school results very right means. To this must be added the sedentariness of the majority of school children in elementary schools that do not benefit from physical activities (or very little) either inside the school or out of school. In this direction the current hot lines for the physical-activity recommend that the children must take part in moderate regular physicalactivities with vigorous during 60 minutes or more each day (Rasberry et al., 2011). The results of a psychological test (WISC: Wechsler Intelligence Scale for Children) on intelligence show that students who receive 5 hours of physical education per week scored higher than students who received the minimum of 40 minutes of physical education per week (Janssen et al., 2011). This represents an additional argument for encouraging out-of-school sports activities for children. Not only the children do not reach the level of physical-activity recommended, but the schools also 
contribute to this culture of physical inactivity (Donnelly \& Lambourne, 2011; Morales et al., 2011). During last years, many school systems eliminated the recreations and / or physical education from their program of studies because of the increasing pressure to increase the school results (Watson et al., 2017).

The regular physical-activity could contribute to improve the intellectual abilities (Marques et al., 2017; Oliveira et al., 2017; Van der Niet et al., 2014). It also improves the cognitive functions, in particular the concentration and the memorizing which one knows the importance in the processes of training (Donnelly et al., 2016; Esteban-Cornejo et al., 2015; Janssen et al., 2014; Maureira \& Diaz, 2017; St-Louis-Deschênes \& Ellemberg, 2013; Van der Fels et al., 2015). However the positive influence of this factor on the school behavior in general and results in particular is established for a long time (St-Louis-Deschênes \& Ellemberg, 2013; Schmidt et al., 2017). The children who are in physical good condition could succeed until twice better on academic tests than those who are not in good physical condition (Sævarsson et al., 2017).

Recent research shows the need to increase the physicalactivity at the children and the teenagers which can be critical for the inversion of the current trends of the disease and also for the improvement of academic success (Bass et al., 2013; Chen et al., 2013; Telford et al., 2012; Tompkins et al., 2012).

\section{Conclusion}

The regular physical-activity and sport deserve to be largely encouraged for the children, taking into account its benefits not only on health, but also on academic performance and cognitive functioning. It would be interesting in future research to determine what is the most influential component of physical activity and sport on school results to help educators (parents, teachers ...) to improve early learning.

\section{References}

Aguado, R.M., Garzarán, A.P., \& Fernández, J.M. (2015). La transmisión de valores a través del deporte. Deporte escolar y deporte federado: relaciones, puentes y posibles trasferencias. RETOS. Nuevas Tendencias en Educación Física, Deporte y Recreación (28).

Álvarez-Bueno, C., Pesce, C., Cavero-Redondo, I., SánchezLópez, M., Garrido-Miguel, M., \& Martínez-Vizcaíno, V. (2017). Academic achievement and physical activity: a meta-analysis. American academy of pediatrics, 140(6). Doi: 10.1542/peds.2017-1498.

Álvarez-Bueno, C., Pesce, C., Cavero-Redondo, I., SánchezLópez, M., Pardo-Guijarro, M. J., \& Martínez-Vizcaíno, V. (2016). Association of physical activity with cognition, metacognition and academic performance in children and adolescents: a protocol for systematic review and metaanalysis. BMJ Open, 6(6). Retrieved from http:// dx.doi.org/10.1136/bmjopen-2016-011065

Bangsbo, J., Krustrup, P., Duda, J., Hillman, C., Andersen, L. B., Weiss, M.,... Elbe, A.M. (2016). The copenhagen consensus conference 2016: children, youth, and physical activity in schools and during leisure time. $\mathrm{Br} \mathrm{J}$ Sports Med, 0, pp. 1-2. Doi: 10.1136/bjsports-2016-096325
Bass, R. W., Brown, D. D., Laurson, K. R., \& Coleman, M. M. (2013). Physical fitness and academic performance in middle school students. Actapcediatrica, 102, 832-837.

Bezold, C. P., Konty, K. J., Day, S. E., Berger, M., Harr, L., Larkin. M., .. . Stark, J. H. (2014). The effects of changes in physical fitness on academic performance among New York City youth. Journal of Adolescent Health, 55(6), 774-781. Doi: 10.1016/j.jadohealth.2014.06.006

Chen, L. J., Fox, K. R., Ku, P. W., \& Taun, C. Y. (2013). Fitness change and subsequent academic performance in adolescents. Journal of School Health, 83(9), 631-638. Retrieved from https://doi.org/10.1111/josh.12075

Coe, D. P., Peterson. T., Blair, C., Schutten, M. C., \& Peddie, H. (2013). Physical fitness, academic achievement, and socioeconomic status in school-aged youth. Journal of School Health. 83(7), 500-508. Doi: 10.1111/ josh.12058.

De Greeff, J., Bosker, R., Oosterlaan, J., Visscher, C., \& Hartman, E. (2018). Effects of physical activity on executive functions, attention and academic performance in preadolescent children: a meta-analysis. Journal of Science and Medicine in Sport, 21(5), 501-507. https:// doi.org/doi: 10.1016/j.jsams.2017.09.595. Epub 2017 Oct 10

Donnelly, J. E., Hillman, C. H., Greene, J. L., Hansen, D. M., Gibson, C. A., Sullivan, D. K.,... Washburn, R. A. (2017). Physical activity and academic achievement across the curriculum: results from a 3-year cluster-randomized trial. US National Library of Medicine National Institutes of Health, 99, 140-145. Doi: 10.1016/j.ypmed.2017.02.006. Epub 2017 Feb 11.

Donnelly, J., Hillman, C., Castelli, D., Etnier, J., Lee, S., Tomporowski, P., ... Szabo-Reed , A. (2016). Physical activity, fitness, cognitive function, and academic achievement in children: a systematic review. Med Sci Sports Exerc, 48(6), 1197-1222. https://doi.org/doi: 10.1249/MSS.0000000000000901

Donnelly, J.E., \& Lambourne K. (2011). Classroom-based physical activity, cognition, and academic achievement. Prev Med, 52 Suppl 1, S36-42. Doi: 10.1016/ j.ypmed.2011.01.021.

Esteban-Cornejo, I., Tejero-Gonzalez, C. M., Martinez-Gomez, D., del-Campo, J., González-Galo, A., Padilla-Moledo, C., ... UP \& DOWN Study Group. (2014). Independent and combined influence of the components of physical fitness on academic performance in youth. J Pediatr, 165(2), 306312. Retrieved from 10.1016/j.jpeds.2014.04.044. Epub 2014 Jun 19.

Esteban-Cornejo, I., Tejero-Gonzalez, C. M., Sallis, J. F., \& Veiga, O. L. (2015). Physical activity and cognition in adolescents: a systematic review. Journal of Science and Medicine in Sport, 18(5), 534-539. Retrieved from https:/ /doi.org/10.1016/j.jsams.2014.07.007

Haapala, E., Väistö, J., Lintu, N., Westgate, K., Ekelund, U., Poikkeus, A., ... Lakka, T. (2017). Physical activity and sedentary time in relation to academic achievement in children. J Sci Med Sport, 20(6), 583-589. Retrieved from https://doi.org/doi: 10.1016/j.jsams.2016.11.003

Howie, E.K., \& Pate, R.R. (2012). Physical activity and academic achievement in children: A historical perspective. Journal of Sport and Health Science, 1(3), 
160-169. Doi: 10.1016/j.jshs.2012.09.003

Janssen, M., Chinapaw, M. J. ., Rauh, S. ., Toussaint, HM, Van Mechelen, W, \& Verhagen, EALM. (2014). A short physical activity break from cognitive tasks increases selective attention in primary school children aged 10 11. Mental Health and Physical Activity, 7(3), 129-134. https://doi.org/ 10.1016/j.mhpa.2014.07.001

Lambourne, K., Hansen, D.M., Szabo, A.N., Lee, J., Herrmann, S.D., Donnelly, J.E. (2013).Indirect and direct relations between aerobic fitness, physical activity, and academic achievement in elementary school students. Ment Health Phys Act, 6(3):165-171.

Marques, A., Gómez, F., Martins, J., Catunda, R., \& Sarmento, H. (2017). Association between physical education, school-based physical activity, and academic performance: a systematic review. Retos, 31, 316-320

Maureira, F. C., \& Díaz, H. M. (2017). Physical exercise and academic performance. MOJ Sports Medicine, 1(4), 9092. https://doi.org/ 10.15406/ mojsm.2017.01.00021

Morales, J., Pellicer-Chenoll, M., García-Massó, X., Gomis. M., \& González, L. M. (2011). Relation between physical activity and academic performance in 3rd-year secondary education students. Perceptual and Motor Skills, 113(2), 539-546. Doi: 10.2466/06.11.13.PMS.113.5.539-546.

Norris, E., Shelton, N., Dunsmuir, S., Duke-Williams, O., Stamatakis, E. (2015). Physically active lessons as physical activity and educational interventions: a systematic review of methods and results. Prev. Med., 72, 116-125.

Oliveira,A.V., Vilaça, R., Santos, C.N., Costa, V., \& Menezes, R. (2017). Exploring the power of yeast to model aging and age-related neurodegenerative disorders. Biogerontology, 18(1), 3-34.

Rasberry, C., Lee, S., Robin, L., Laris, B., Russell, L., Coyle, K., \& Nihiser,A. (2011). The association between schoolbased physical activity, including physical education, and academic performance: a systematic review of the literature. Prev Med, 52. https://doi.org/doi: 10.1016/ j.ypmed.2011.01.027

Raven, J. C. (1998). Raven’s Coloured Progressive Matrices (CPM).Coloured Progressive Matrices (CPM). Manual Section 1 General Overview (1998 Edition, Updated 2003).

Resaland, G. K., Aadland, E., Moe, V. F., Aadland, K. N., Skrede, T., Stavnsbo, M., .. .Anderssen, S. A. (2016). Effects of physical activity on schoolchildren's academic performance: The Active Smarter Kids (ASK) clusterrandomized controlled trial. Preventive Medicine, 91, 322328. Doi: 10.1016/j.ypmed.2016.09.005

Sævarsson, E., Svansdottir, E., Sveinsson, T., Asgeirsdottir, T., Arngrimsson, S., \& Johannsson, E. (2017). Organized leisure-time sport participation and academic achievement in preadolescents. Scand J Public Health, 45(8), 861868. https://doi.org/10.1177/1403494817705560

Schmidt, M., Egger, F., Benzing, V., Jäger, K., Conzelmann, A., Roebers, C. M., \& Pesce, C. (2017). Disentangling the relationship between children's motor ability, executive function and academic achievement. PLoS ONE, 12(8). https://doi.org/https://doi.org/10.1371/ journal.pone.0182845

Singh, A., Uijtdewilligen , L., Twisk , J., van Mechelen, W., \& Chinapaw , M. (2012). Physical activity and performance at school: a systematic review of the literature including a methodological quality assessment. Arch Pediatr Adolesc Med, 166(1), 49-55. https://doi.org/10.1001/ archpediatrics.2011.716

St-Louis-Deschênes, M., \& Ellemberg, D. (2013). L'exercice physique aigue la performance cognitive chez l'enfant et l'adolescent. Science \& Sports, 28, 57-64. https://doi.org/ https://doi.org/10.1016/j.scispo.2011.10.007

Telford, R. D., Cunningham, R. B., Fitzgerald, R., Olive, L. S., Prosser, L., Jiang, X., \& Telford, R. M. (2012). Physical education, obesity, and academic achievement: a 2-year longitudinal investigation of Australian elementary school children. American Journal of Public Health, 102(2),368-374. Doi: 10.2105/AJPH.2011.300220

Tompkins, C.L., Hopkins, J., Goddard, L., \& Brock, D.W. (2012).The effect of an unstructured, moderate to vigorous, before-school physical activity program in elementary school children on academics, behavior, and health. BMC Public Health, 12, 300. https://doi.org/ 10.1186/1471-2458-12-300

Tomporowski, P., McCullick, B., Pendleton, D.M., \& Pesce, C. (2015). Exercise and children's cognition: The role of exercise characteristics and a place for meta cognition. Journal des sciences du sport et de la santé, 4 (1), 47-55. Doi: 10.1016/j.jshs.2014.09.003.

Tomporowski, P.D., Lambourne, K., \& Okumura, M.S. (2011). Physical activity interventions and children's mental function: An introduction and overview. Prev Med, 52(S1), S3-9. Doi: 10.1016/j.ypmed.2011.01.028. Epub 2011 Mar 21. Review.

Tremblay, M.S., Inman, J.W., Willms, J.D. (2000). The relationship between physical activity, self-esteem, and academic achievement. Pediatric Exercise Science, 12, 312-323.

Van der Fels, I., TeWierike, S., Hartman, E., Elferink-Gemser, M., Smith, J., \& Visscher, C. (2015). The relationship between motor skills and cognitive skills in 4-16 year old typically developing children: A systematic review. J Sci Med Sport, 18(6), 697-703. https://doi.org/10.1016/ j.jsams.2014.09.007

Van der Niet, A.G, Hartman, E., Smith, J., \& Visscher, C. (2014). Modeling relationships between physical fitness, executive functioning, and academic achievement in primary school children. Psychology of Sport and Exercise, 15(4), 19-325.https://doi.org/ https://doi.org/ (...)ychsport.2014.02.010

Van Dusen, D., Kelder, S., Kohl, H., Ranjit, N., \& Perry, C. (2011). Associations of physical fitness and academic performance among school children. Journal of School Health, 81(12), 733-740. https://doi.org/10.1111/j.17461561.2011.00652.x

Watson, A., Timperio, A., Brown, H., Best, K., \& Hesketh, K. (2017). Effect of classroom-based physical activity interventions on academic and physical activity outcomes: a systematic review and meta-analysis. Journal of Behavioral Nutrition and Physical Activity, 14(1), 114. https://doi.org/10.1186/s12966-017-0569-9

Wittberg, R., Northrup, K., \& Cottrell, L. (2012). Children's aerobic fitness and academic achievement: a longitudinal examination of students during their fifth and seventh grade years. Am J Public Health, 102(12), 2303-7. https:/ /doi.org/10.2105/AJPH.2011.300515 